ANÁLISE DAS RELAÇÕES FILOGENÉTICAS E DISTRIBUIÇÃO GROGRÁFICA ATUAL DOS GÊNEROS DE CHARACIDAE SULAMERICANOS (TELEOSTEI: CHARACIFORMES)

\title{
PHYLOGENETIC RELATIONSHIPS ANAIYSIS AND CURRENT GEOGRAPHIC DISTRIBUTION OF SOUTH AMERICAN CHARACIDAE (TELEOSTEI: CHARACIFORMES)
}

\author{
STUFF, Travis'; ${ }^{1}$ SILVA, Lucas Gonçalves ${ }^{2 *}$ \\ ${ }^{1}$ School of Biological Sciences, University of Sydney. \\ Level 5, Building F07 - Carslaw, Sydney, Austrália.

\begin{abstract}
* Autor correspondente
e-mail: lucas.silva@pucrs.br
\end{abstract} \\ ${ }^{2}$ Departamento de Biodiversidade e Ecologia, Pontifícia Universidade Católica do Rio Grande do Sul. \\ Campus Central da PUCRS - Av. Ipiranga, 6681, Prédio 12C, Sala 172, 90610-001, Porto Alegre-RS, Brasil.
}

Received 21 January 2011; received in revised form 29 April 2011; accepted 03 May 2011

\section{RESUMO}

A família de peixes Characidae é uma das mais diversificadas em número de espécies descritas e insuficientemente conhecida do ponto de vista filogenético. Através da análise de seqüências do gene RAG2 de representantes de todos os gêneros de ocorrência na América do Sul e consulta às bases de dados de coleções ictiológicas do Brasil, foi obtida uma filogenia dos gêneros e sobre análise do padrão de distribuição geográfica das espécies de acordo com os principais sistemas hidrográficos sul-americanos. A nova filogenia resolve grupos anteriormente incertos e evidencia algumas novas relações filogenéticas dentro do grupo e, adicionalmente, pela primeira vez uma análise da distribuição geográfica dos gêneros de Characidae sulamericanos é ilustrada.

Palavras-chave: Characidae, Distribuição geográfica, filogenia, RAG2, América do Sul.

\begin{abstract}
The fish family Characidae is one of the most diverse in number of species and poorly described from a phylogenetic standpoint. By analyzing RAG2 gene sequences of all representatives genera occurring in South America and query the databases of brazilian ichthyological collections, it was obtained a phylogeny of the genus and the patterns analysis of the geogrphical distribution of species in the major South America basins. The new phylogeny resolves groups which showed some uncertain phylogenetic relationships and, additionally, for the first time an analysis of geographical distribution of South American genera of Characidae is illustrated.
\end{abstract}

Keywords: Characidae, geographic distribution, phylogeny, RAG2, South América.

PERIÓDICO TCHÊ QUÍMICA • www.periodico.tchequimica.com • Vol. 8 N. 16.

- ISSN 1806-0374 (impresso) • ISSN 1806-9827 (CD-ROM) • ISSN 2179-0302 (meio eletrônico)

(C) 2011. Porto Alegre, RS. Brasil 


\section{INTRODUÇÃO}

A Ordem Characiformes está entre as mais diversificadas ordens de peixes de água doce, com mais de 1600 espécies viventes (Daget \& Gosse, 1984; Reis et al., 2003). Sua distribuição abrange a África, Américas do Sul e Central e a parte sul da América do Norte (McConnel, 1975). A maior diversidade de espécies é encontrada na região Neotropical (14 famílias e aproximadamente 1460 espécies, cerca de $21 \%$ da fauna de peixes dessa região) e há registros para 4 famílias e 208 espécies no continente africano (Winemiller, 1996).

A filogenia da Ordem Characiformes não é totalmente resolvida e os limites taxonômicos e filogenéticos também não são evidentes. Alguns estudos já publicados analisaram gêneros da ordem através de morfologia das espécies, tal como Vari (1979) e Brewster (1986). E outros autores como Ortí \& Mayer (1997) e Calcagnotto et al. (2005) obtiveram filogenias do grupo a partir de seqüências de genes. Análises de seqüências de DNA podem resolver grupos ainda não bem definidos dentro da Ordem Characiformes, como os peixes da família Characidae (família-tipo da Ordem), que possuem grande representatividade na região Neotropical e acentuada importância ecológica e comercial (Calcagnotto et al., 2005). Da mesma forma, a biogeografia e a distribuição de peixes neotropicais ainda estão em processo de caracterização. Boa parte da fauna de peixes neotropicais ainda está em processo de documentação cientifica, sendo que freqüentemente novas espécies estão sendo descritas e novas relações de biogeografia de peixes vão sendo publicadas em estudos mais atualizados (Vari \& Malabarba, 1998; Dominguez et al., 2006). As deficiências taxonômicas descritas têm reflexos profundamente negativos em quaisquer estudos de sua evolução, ecologia, conservação, manejo e uso sustentável, já que cabe à sistemática produzir e manter os mais fundamentais sistemas gerais de organização da diversidade biológica.

O objetivo do presente estudo é obter uma filogenia da família Characidae, através de análises de seqüências do gene RAG2 de espécies representativas dos gêneros de ocorrência sul-americana da família e compreender as relações filogenéticas e moleculares, em função da distribuição geográfica desses gêneros.

\section{MATERIAL E MÉTODOS}

$\mathrm{Na}$ presente análise, foram utilizadas seqüências do gene nuclear RAG2 (Recombination activating gene). A opção por utilização desse gene para as análises está diretamente relacionada com a disponibilidade de dados, já que é o único gene seqüenciado em todos os gêneros de Characidae. Os números de acesso direto das seqüências utilizadas no NCBI Genbank estão disponíveis no anexo 1.

As informações que serviram de base para o presente artigo e a metodologia para obtenção das seqüências estão publicadas no trabalho de Calcagnotto et al. (2005). A análise das seqüências partiu de um alinhamento utilizando a função CLUSTAL W com parâmetros default no software MEGA 5.0.

A análise filogenética foi realizada pela metodologia bayesiana do pacote BEAST 1.5.4, com formulação do modelo através do software BEAUTi (parâmetros default, modelo GTR de substituições, modelo de heterogeneidade Gamma e modelo de relógio molecular relaxado lognormal), obtido através do software ModelTest 0.1 .1 , que identifica o melhor desenho de modelo evolutivo para o alinhamento em análise. Os resultados foram gerados através do software TreeAnotator, a visualização das corridas através do software TRACER (10.000.000 estados e 100.000 burn-in) e o cladograma final de consenso exposto pelo software FigTree 1.3.1 (Fig. 1).

Para a análise biogeográfica, foi utilizada a base de dados de Hubert \& Renno (2006), que traz dados referentes à biogeografia de peixes neotropicais, com divisão pelas principais regiões hidrográficas da América do Sul. No artigo de Hubert \& Renno (2006), a América do Sul está dividida em 6 grandes regiões hidrográficas (Andes, Orinoco, Suriname, Amazonas, Bacia do Prata e Bacia do Atlântico) e o mesmo padrão hidrográfico foi mantido para o proposto estudo. A partir da coleta de informações dos gêneros de Characidae de interesse no sistema SIBIP/NEODAT III, que possui os registros de coleções ictiológicas de instituições de pesquisa 
do Brasil (Tab. 1), foram geradas classificações dos gêneros com base nas grandes regiões hidrográficas propostas por Hubert \& Renno (2006). Foram computados todos os registros de espécies disponíveis para cada gênero de interesse disponíveis no sistema.

\section{RESULTADOS E DISCUSSÃO}

A filogenia dos gêneros sul-americanos da família Characidae, obtida através de rotinas de análise filogenética dos softwares e modelos descritos está mostrada na Figura 1, resultante de uma única árvore de 1071 passos. Os valores de likelihood foram -7142,547 (mean) e 2131,952 (ess), resultando em um tracer (análise de compatibilidade) bastante homogêneo. Todos os demais parâmetros de análise também ficaram dentro de intervalos ótimos. A distribuição geográfica dos gêneros está evidenciada na Tabela 1. É perceptível um domínio de ocorrência dos diferentes gêneros de Characidae na região hidrográfica do Amazonas e uma distribuição mais restrita na região hidrográfica do Suriname.

Muitas semelhanças foram encontradas entre as filogenias obtidas no presente estudo e também em comparativo com a obtida por Calcagnotto et al. (2005), onde foram publicados dados a partir de diversos genes de todos os gêneros de Characidae. O clado que engloba os gêneros Aphyocheirodon, Cheirodon, Cheirodontops, Prodontocharax, Exodon e Roeboides é exatamente o mesmo nos dois estudos e nos cladogramas obtidos, apresentando as mesmas relações filogenéticas. O mesmo acontece com o clado que relaciona os gêneros Astyanax, Astyanacinus, Inpaichthys, Moenkhausia, Hemigrammus e Hypressobrycon. O grupo monofilético formado pelos gêneros Knodus, Bryconamericus,

Creagrutus, Hemibrycon, Gephyrocharax e Mimagoniates possui algumas divergências entre o presente estudo e de Calcagnotto et al. (2005), no qual o gênero Hemibrycon encontra-se como grupoirmão de Bryconamericus, Knodus e Creagrutus, quanto no presente trabalho o mesmo gênero é grupo-irmão de todos os outros gêneros desse grupo monofilético.

Entretanto, as maiores divergências entre as filogenias obtidas estão no grupo formado pelos gêneros Triportheus, Salminus, Brycon,
Ancestrorhynchus, Bryconops e Chalceus. A filogenia desse subgrupo fica difícil de ser inferida através da análise de seqüências do gene em questão, apesar da resolução dos grupos nas análises do pacote BEAST. Portanto, seria de interesse estudos com a inclusão de novos genes nessa análise, para melhor resolução dessas incongruências.

Com relação à distribuição geográfica dos gêneros, Chalceus, Cheirodontops, Prodontocharax, Impaichthys e Hemibrycon são exclusivos de apenas uma região hidrográfica, enquanto Roeboides e Brycon encontram-se em todas as regiões. Os gêneros grupo definido como monofilético na filogenia obtida no presente estudo composto por Hemigrammus, Hypressobrycon, Astyanacinus, Astyanax, Impaichthys e Moenkhausia estão todos presentes na região amazônica, e alguns deles em outras regiões, como Prata e Atlântico. O gênero Hemigrammus é o único deste grupo monofilético que ocorre na região do Suriname e, nenhum dos gêneros citados, está presente na região hidrográfica do Orinoco, o que sugere eventos de dispersão ou vicariância de espécies dos gêneros deste grupo. Pode-se inferir uma origem na região amazônica, já que todos os gêneros encontram-se presentes. $O$ gênero Hemibrycon está presente somente na região amazônica e, outros gêneros que fazem parte de seu grupo monofilético, como Creagrutus, Bryconamericus e Knodus também possuem distribuição na mesma região. Isso corrobora a filogenia proposta por Calcagnotto et al. (2005), onde Hemibrycon é grupo-irmão direto desses outros gêneros, o que não ocorre no presente estudo. Neste trabalho os gêneros monofiléticos Mimagoniates e Gephyrocharax estão representados como grupo-irmão direto de Creagrutus, Bryconamericus e Knodus, e possuem distribuição mais restrita que os demais, e distinta entre si (Andes/Orinoco e Bacia do Prata/Bacia do Atlântico, respectivamente).

O gênero Exodon ocorre somente na parte norte do continente (Orinoco/Suriname/Amazonas), enquanto e os demais gêneros de seu grupo monofilético estão amplamente distribuídos em toda América do Sul. O clado não bem resolvido na filogenia do grupo também é amplamente distribuído no continente, com ocorrência na grande maioria das regiões hidrográficas, podendo ser um 
indicativo que rápidas mudanças adaptativas ocorreram dentro do clado. No trabalho de Weitzman \& Malabarba (1998), através de análises morfológicas e de distribuição dos gêneros de Characidae, foi definido que os gêneros Brycon, Salminus e Triportheus estão mais relacionados entre si do que com Acestrorhynchus, o que em parte não é corroborado pela análise filogenética a partir de seqüências do gene RAG2 e pela distribuição dos gêneros na América do Sul no presente estudo.

\section{AGRADECIMENTOS}

Os autores gostariam de agradecer ao Departamento de Biodiversidade e Ecologia da PUCRS e School of Biological Sciences (Sydney) pelo apoio logístico e ao CNPq (Brasil) pelo apoio financeiro ao presente estudo.

\section{REFERÊNCIAS}

1. Brewster, B. 1986. A review of the genus Hydrocynus Cuvier 1819 (Teleostei: Characiformes). Bull. Br. Mus. Nat. Hist. (Zool.) 50 (3): 163-206.

2. Calcagnotto, D., Shaefer, S. A., DeSalle, R. 2005. Relationships among characiform fishes inferred from analysis of nuclear and mitochondrial gene sequences. Molecular Phylogenetics and Evolution 36: 135-153.

3. Daget, J., Gosse, J. P., Audenaerde, D. F. E. 1984. Checklist of the freshwater fishes of Africa. Volume I., ORSTOM, Paris, p. 410.

4. Dominguez, O. D., Doadrio, I., Leon, G. P. P. 2006. Historical biogeography of some river basins in central Mexico evidenced by their goodeine freshwater fishes: a preliminary hypothesis using secondary Brooks parsimony analysis. Journal of Biogeography 33: 1437-1447.
5. Hubert, N., Renno, J. F. 2006. Historical biogeography of South American freshwater fishes. Journal of Biogeography 33: 1414-1436.

6. McConnel, R. 1975. Fish communities in tropical freshwaters. Longman Publishing, New York.

7. Ortí, G., Mayer, A. The radiation of characiform fishes and the limits of resolution of mitochondrial ribosomal DNA sequences. Syst. Biol. 46: 75-100.

8. Reis, R. E., Kullander, S. O., Ferraris, C. J. 2003. Check list of the freshwater fishes of South and Central America. EdiPucrs, Porto Alegre, Brazil p. 742.

9. Tamura, K., Dudley, J., Masatochi, N., Kumar, S. 2007. MEGA 4 (Molecular Evolutionary Genetics Analysis).

10. Vari, R. P. 1979. Anatomy, relationships and classification of the families Citharinidae and Distichodontidae (Pisces: Caracoidei). Bull. Brit. Mus. Nat. Hist. (Zool.) 36(5): 261-344.

11. Weitzman, S. H., Malabarba, L. R. 1998. Perspectives about the phylogenyn and classification of the Characidae (Teleostei: Characiformes). In: Malabarba, L. R., Reis, R. E., Vari, R. P., Lucena, Z. M. S., Lucena, C. A. S. (Eds.), Phylogeny and Classification of Neotropical Fishes. EdiPucrs, Porto Alegre, pp. 161170.

12. Winemiller, K. O. 1996. Dynamic diversity: Fish communities of tropical rivers. In: Cody, M. L., Smallwood, J. A. (Eds.). Long-term studies of vertebrate communities. Academic Press, Orlando, FL, pp. 99-134.

13. Vari, R. P.; Malabarba, L. R. 1998. Neotropical Ichthyology: An overview. Phylogeny and classification of Neotropical fishes. Porto Alegre: EdiPUCRS, 603 pp. 
(A)
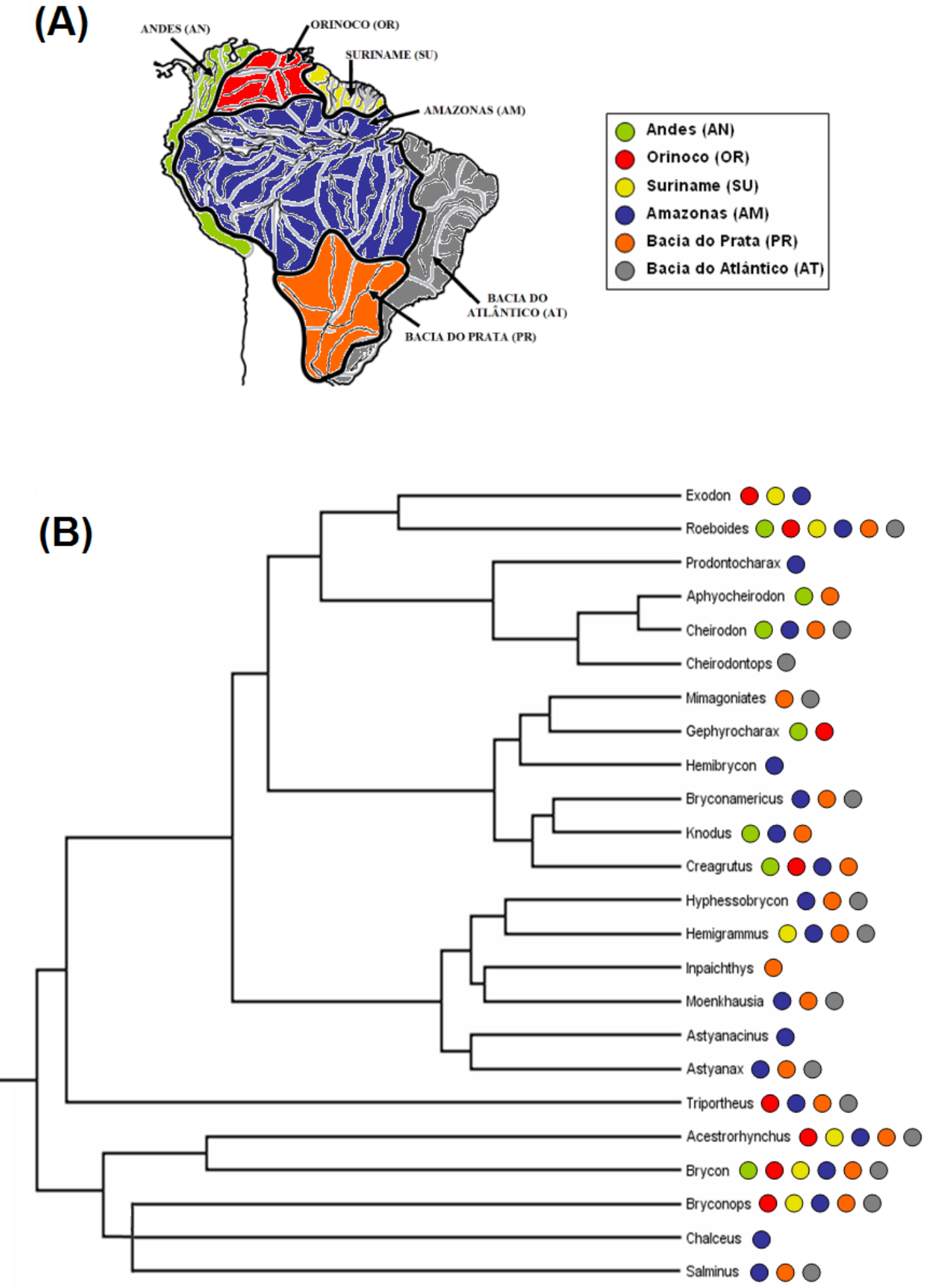

Figura 1. Análise bayesiana do pacote BEAST 1.5.4. Relações filogenéticas entre os gêneros de Characidae neotropicais e ocorrências nas regiões hidrográficas propostas por Hubert \& Renno (2006).

PERIÓDICO TCHÊ QUÍMICA • www.periodico.tchequimica.com • Vol. 8 N. 16. • ISSN 1806-0374 (impresso) • ISSN 1806-9827 (CD-ROM) • ISSN 2179-0302 (meio eletrônico) (C) 2011. Porto Alegre, RS. Brasil 
Tabela 1. Ocorrência dos gêneros de Characidae neotropicais nas grandes regiões hidrográficas da América do Sul propostas por Hubert \& Renno (2006). Dados do sistema SIBIP NEODAT III.

\begin{tabular}{|c|c|c|c|c|c|c|}
\hline Gêneros/Bacias & ANDES & ORINOCO & SURINAME & AMAZONAS & PRATA & ATLÂNTICO \\
\hline Acestrorhynchus & & $X$ & $X$ & $X$ & $X$ & $X$ \\
\hline Aphyocheirodon & $x$ & & & & $x$ & \\
\hline Astyanacinus & & & & $\boldsymbol{x}$ & & \\
\hline Astyanax & & & & $x$ & $\boldsymbol{x}$ & $\boldsymbol{x}$ \\
\hline Brycon & $\boldsymbol{X}$ & $\boldsymbol{x}$ & $\boldsymbol{x}$ & $x$ & $x$ & $x$ \\
\hline Bryconamericus & & & & $x$ & $x$ & $x$ \\
\hline $\begin{array}{c}\text { Bryconops } \\
\text { Chalceus }\end{array}$ & & $x$ & $\boldsymbol{x}$ & $\begin{array}{l}x \\
x\end{array}$ & $x$ & $x$ \\
\hline Cheirodon & $x$ & & & $x$ & $x$ & $x$ \\
\hline Cheirodontops & & & & & & $\boldsymbol{x}$ \\
\hline $\begin{array}{l}\text { Creagrutus } \\
\text { Exodon }\end{array}$ & $x$ & $\begin{array}{l}x \\
x\end{array}$ & $\boldsymbol{x}$ & $\begin{array}{l}x \\
x\end{array}$ & $x$ & \\
\hline $\begin{array}{c}\text { Gephyrocharax } \\
\text { Hemibrycon }\end{array}$ & $x$ & $x$ & & $\boldsymbol{x}$ & & \\
\hline Hemigrammus* & & & $\boldsymbol{x}$ & $x$ & $\boldsymbol{x}$ & $\boldsymbol{x}$ \\
\hline $\begin{array}{l}\text { Hyphessobrycon } \\
\text { Inpaichthys }\end{array}$ & & & & $x$ & $\begin{array}{l}x \\
x\end{array}$ & $x$ \\
\hline Knodus & $x$ & & & $\boldsymbol{x}$ & $x$ & \\
\hline Moenkhausia & & & & $\boldsymbol{x}$ & $x$ & $\boldsymbol{x}$ \\
\hline Mimagoniates & & & & & $x$ & $\boldsymbol{x}$ \\
\hline Prodontocharax & & & & $\boldsymbol{x}$ & & \\
\hline Roeboides & $\boldsymbol{x}$ & $\boldsymbol{x}$ & $x$ & $x$ & $\boldsymbol{x}$ & $\boldsymbol{x}$ \\
\hline Salminus & & & & $\boldsymbol{x}$ & $\boldsymbol{x}$ & $\boldsymbol{x}$ \\
\hline Triportheus & & $\boldsymbol{x}$ & & $x$ & $x$ & $x$ \\
\hline
\end{tabular}

*Gênero com registro em Trinidad e Tobago 
Anexo 1. Números de acesso do NCBI Genbank das seqüências de gêneros de Characidae de interesse para análise filogenética a partir do gene RAG2.

\begin{tabular}{|c|c|}
\hline Gênero & Número de acesso NCBI Genbank \\
\hline Acestrorhynchus & AY804026 \\
\hline Aphyocheirodon & AY804031 \\
\hline Astyanacinus & AY804033 \\
\hline Astyanax & AY804025 \\
\hline Brycon & AY804046 \\
\hline Bryconamericus & AY804048 \\
\hline Bryconops & AY804049 \\
\hline Chalceus & AY804060 \\
\hline Cheirodon & AY804057 \\
\hline Cheirodontops & AY804058 \\
\hline Creagrutus & AY804062 \\
\hline Exodon & AY804072 \\
\hline Gephyrocharax & AY804073 \\
\hline Hemibrycon & AY804079 \\
\hline Hemigrammus & AY804076 \\
\hline Hyphessobrycon & AY804080 \\
\hline Inpaichthys & AY804093 \\
\hline Knodus & AY804094 \\
\hline Moenkhausia & AY804104 \\
\hline Mimagoniates & AY804101 \\
\hline Prodontocharax & AY804109 \\
\hline $\begin{array}{l}\text { Roeboides } \\
\text { Salminus }\end{array}$ & $\begin{array}{l}\text { AY804056 } \\
\text { AY804124 }\end{array}$ \\
\hline Triportheus & AY804125 \\
\hline
\end{tabular}

PERIÓDICO TCHÊ QUÍMICA • www.periodico.tchequimica.com • Vol. 8 N. 16. • ISSN 1806-0374 (impresso) • ISSN 1806-9827 (CD-ROM) • ISSN 2179-0302 (meio eletrônico) (C) 2011. Porto Alegre, RS. Brasil 